tion at right angles to the leakage field. Unless the width of the conductors is small, therefore, high densities of leakage fiux are not permissible, on account of the resulting abnormal copper loss, and the corresponding increase in heating, and decrease in efficiency.

Perhaps the first use of high reactance in transformers was that referred to above, to obtain in the secondary, constant current rather than constant potential for purposes of arc lighting. Here, however, not a constant reactance, but a variable one was needed. High reactance was here obtained without high densities in the leakage flux, by providing a large cross sectional area of the leakage field rather than many turns : and since the conductors were not large, no especia difficulty was experienced with eddy currents. The indifficulty was experienced with eddy currents. The in-
creased reactance for partial load conditions in these creased reactance for partial load conditions in these
transformers is obtained, by moving the primary farther and farther away from the secondary, so that the leakage flux is increased by increasing the area of cross section of its field, the density remaining constant.

This method of obtaining high reactance is very expensive because of the great length of core that is necessary to surround this idle space, in addition to surrounding the copper and insulation and is prohibitive in large units. The reactance that can be obtaine economically, without a density of leakage flux which is not too high from the standpoint of eddy current loss, varies with the voltage of the transformer, for the higher the voltage the greater the distance that must necessarily exist between primary and secondary must necessarily exist between primary and secondary windings for insulation purposes, and therefore the
greater the amount of flux that can be carried through this space without serious eddies in the copper. Thu it may be as easy to make a transformer with 10 per cent reactanice when wound for 100,000 volts as for 5 per cent reactance when wound for 25,000 volts, due to the broader path that exists for the reactive flux in the high voltage design.

As a general proposition, it may be said that it is usually impractical to get more than 8 per cent reactance in 60-cycle transformers without undue eddy current losses, and that the allowable maximum would be considerably less than this in low-voltage designs. For lower frequency, higher reactance may be practical,
since eddy current losses are less at a given density.

since eddy current losses are less at a given density.
It has recently become customary to specify that the transformer must not have less than, say 5 per cent reactance, for the protection of transformers, switches generators, and in fact all parts of the system against the high mechanical stresses due to excessive currents. It is not always appreciated, however, that limiting the current in this way, while protecting other apporatus, does not necessarily make the transformer any safer to withstand overload conditions.

Calculations for the mechanical stresses in the transformer may be made by the equation, Mechanical stress $=$

$$
\text { (Turns) })^{2} \times(\text { Current })^{2}
$$

(Length of leakage path $)^{2} \times$ (Number of groups) $^{2}$ $X$ a constant

where the group

Mechanical stress $=$

$$
\text { (Turns) })^{2} \times(\text { Currents })^{2}
$$

(Length of leakage path) ${ }^{2}$

where the turns considered are not the total of the transformer, but the turns in that group which has the maximum number.
From the above equations, it may be seen that when high reactance is obtained by massing the turns in a
small number of groups, the "turns" factor of the exsmall number of groups, the "turns" factor of the expression for mechanical stress is increased, though th groups are not kept equal to each other, the maximum stress, which occurs in the maximum group, and which produces the forces that are felt by the core and coil supports, is likely to be actually greater under short circuit conditions for a high reactance transformer than for a low reactance one.

With equal numbers of turns in all the groups, the forces will be greater for the low reactance transformer than for the high reactance one at absolute short circuit with full voltage maintained on the primary terminals, although not enough greater to make a ver serious difference in any case where the supports are designed to supply a proper factor of safety for the high reactance transformer. Moreover, with a definite fixed current flowing, the force will be much smaller for the low reactance transformer than for the high reactance one, and with a comparatively small external impedance, in addition to the impedance of the transformer, the force due to short circuit becomes less for the low reactance transformer than for the high reactance one.

From the above it will be seen that very little is to be gained from the standpoint of safety to the transformer by the introduction of high reactance within the transformer itself. It is true that this would protect other parts of the system. but the additional reactance would be equally as effective for this purpose outside of the transformer as inside of it

This is illustrated by Fig. 1, which shows the mechanical stresses under short circuit conditions, in a transformer designed for 2 per cent reactance and in the same transformer when redesigned for 5 per cent reactance. It is assumed that constant voltage is maintained at the primary terminals. With normal current only flowing, the mechanical stresses in the high reactance design are higher than in the low reactance design, but when short circuit occurs at the secondary terminals, the stress is higher in the low reactance design. This is shown on the curve for zero external reactance. With the addition of about 1 per cent external reactance, the curves cross and with further increase in external reactance, the high reactance transformer is subjected to the greatest strains.

With 3 per cent external reactance added to the low reactance design and none to the high reactance design, thus making the total in both cases 5 per cent, the stress in the former is only about one fourth as great as that in the latter.

When short circuit occurs at some distance from the transformer, the reactance of the lines adds to the transformer reactance and serves to reduce the stresses on the transformer. In fact, in this case the line resistance also assists, and a smaller value of external reactance will cause the two curves to cross and the stresses in the low reactance design to become less than those in the high reactance design.

The effort to obtain sufficient reactance for current limiting purposes in an auto-transformer is a more diffcult problem. These are frequently used for a one-totwo ratio of transformation, as, for instance, in stepping-up the voltage of a 10,000 -volt generator to 20,000 volts. Here the auto-transformer has only half the rolts. Here the auto-transformer has only half the on the system is only one half that of its own inherent reactance. In some cases where it is necessary to get the equipment in the smallest possible space or keep to the lowest possible costs, it is necessary to be satis-
fied with what current-limiting reactance can be placed in the system by such an auto-transformer, but an exceedingly rigid design of coil supports then becomes necessary.

When greater amounts of reactance are desired for Wexibility in ratio of transformation, as for use with synchronous converters, the result can be obtained by placing a laminated iron structure between primary and secondary in such a way as to form a path for the leakage flux. If this iron path is of such a section as to carry the flux corresponding to the desired reactance without approaching saturation, the copper will be entirely shielded from eddy currents, and the transformer's reactance may be increased almost without limit. It is evident, however, that the use of such a device daes not extend the possibility of current-limiting reqotance, as the amount of iron that would be necessary to carry the entire flux on short circuit would result in a prohibitive amount of reactance, from a regulation standpoint, at normal loads.

It is interesting to note that this use of an iron path for the reactive flux, as well as the high reactance design in which the flux is entirely within the air space between primary and secondary, was first de veloped in connection with arc lighting apparatus, where transformers with a fixed high reactance were used to obtain regulation characteristics approaching constant current. The proportioning of these flux shunts for transformers with regulating reactance is an interesting and not altogether easy problem, and it may be of sufficient interest, in view of the fact that it has been so recently reduced to practice, to be worthy of comment here.

Evidently there must be as many shunts as there are spaces between primary and secondary groups. Evidently, also, the section of these shunts must bear the same relation to the section of the core of the transformer as the reactance voltage bears to the full voltage of the transformer. This on the assumption that the density in the shunt at full load is to be the same as the normal density in the core at normal voltage. However, it is usually the case that if a straight line characteristic is to be obtained in the reactance, say, up to 50 per cent overload, the section of each of these shunts must be somewhat larger than this; that is, for 15 per cent reactance the section of the shunt will have to be perhaps 20 per cent of the section of the transformer core.

Again, it is necessary to have air gaps in this circuit: First, because a straight line characteristic cannot be obtained with any magnetic circuit that is a closed iron circult; and second, because in any group of ampere turns that would be practical, a sufficient magnetomotive force would be obtained to oversaturate the shunt circuit at full load if there were only the reluctance of the iron circuit to limit the flux. It should be noted that the loss in these shunts is not a constant one like core loss, but various with the load; consequently, it affects efficiency as if it were a coppe loss. However, the loss in the shunts is small as their weight is very small compared with the weight of the

Figs. 2 and 3 illustrate the manner in which these flux shunts are placed in core type and shell type designs, ręspectively.

Figs. 4 and 5 show the general appearance of the concrete core external reactance which have been de veloped and successfully used in large power systems to limit the flaw of current at short circuit.

\title{
Modern White Pigments
}

\section{Their Manufacture and Properties}

\section{By C. A. Klein}

Tнe subject of paints has of recent years become one on which public attention has been focussed, largel in consequence of the incidence of lead poisoning which is observed among those engaged in the manufacture and use of paints containing a lead base, and this has been an important factor in the recent history of th development of the paint industry. It is only withi the last fow years that white lead has encountere any serious opposition, although substitutes of various kinds have been offered for many years. The progress of the present substitutes is the direct outcome of the application of experience gained after extensive and costly experiments. In the early days it was soon discovered that substitutes must have properties other than dazzling whiteness and chemical purity, and further that the necessary properties were not easily - Reproduced from The Chemical World. attained. The patent records cover an enormous range of white substances, few of which have proved of any practical value. It is only proposed to deal with white pigments in this article, as either alone or as basis for colored paints, such pigments constitute the greatest portion of the paint now used.

For years a keenly conducted controversy has been merits of regard to the respective merits and deof the writer is lead and its substitutes, and the objeot give a short account of the products which at the present time are of commercial importance.

The controversy can only be settled after careful and organized investigation, and at the outset demands some definite agreement as to a basis of comparison for the different purposes for which paint is used; e. g., indoor, outdoor, exposure to sea air, etc. If such an agreement was made it would go far toward a set- tlement and there would be less angument as to the ezact meaning of such expressiops as "covering power," et3., which at the present time have meanipes which vary considerably. Comparison can only be made on broad lines, and the basis must be so comprehensive as to merit the term "painting value," in which al the factors which determine the provision of a well decorated and protected surface, have received due reoognition, e. g., cost of materials, cost of application, life of paint, cost of repainting, etc.

The failure of many of the earlier substitutes has been responsible for a marked conservative attitude in the painter, whioh is not conducive to the neceseary co-operation of theory and practice, but this barrier is slowly being removed and more desire to try new materials is apparent.

At the present time it cannot be maintained that 
any single known pigment is ideal for all purposes, and the possible preparation of such a product appears doubtful. It is not improbable that the solution of the problem lies in the proper selection of the pigment or mixture of pigments whose properties are most desirable for the proposed work

It has been clearly shown that the weakness of on pigment can be removed by the addition of other pigments, and that in many cases a mixture is advantageous. The present white pigments now in use in any considerable quantities number only four, viz, white lead, basic lead sulphate, zinc oxide, and lithopone, and the following notes give outlines of the history and manufacture of these four products.

White Lead.-The early history of white lead is of great antiquity, and presents few interesting features from a scientific standpoint, except that the records show that the conversion of metallic lead into carbonate was by means of the acetate, a feature which still holds in all present processes, though it is of interest to note that recently a patent was granted for terest to note that recently a patent was granted for
the use of amino acids, which indicates a desire to the use of amino acids, which indicates a desire to depart from the time-honored and effective method The Dutch Stack method is the oldest process now adopted, and all other existing processes have been designed with a view to more quickly carrying out by various means the reactions known to take place by various means the reactions known to take place
in the stacks. In the ordinary stack process a period in the stacks. In the ordinary stack process a period of about ninety days is required for conversion of
the metal into carbonate, whercas in some of the newer processes the complete operation occupies less than twelve hours.

Although the actual Dutch Stack process has not been subject to much alteration for many years past, there has within recent years been very considerable advance from a chemical and mechanical standpoint, and much bacteriological work has been carried out with the object of controlling the fermentation of the tan or other waste product used for the produc tion of carbonic acid gas. These advances have doubtless been necessitated by the progress made by the more recent quick processes which have after many reverses been firmly established in various countries. reverses been firmly established in various countries. which claims to show the closest mechanical relationship to the stack method, consists in the exposure of thin sheets of lead to artificially-produced carbon dioxide and steam in the presence of acetic acid vapor. The process is used in England and largely in Germany, but curiously has not found application in the United States of America. The product is of excellent color and occupies a recognized position among users. Modiand occupies a recognized position among users. Modj-
fications of the chamber process, where still larger surfaces of metal are exposed, e. g., lead sponge and fiber have been tried with varying success. In the United States of America processes are in use in which finelydivided lead is oxidized and hydrated and afterward converted into basic carbonate by means of purified boiler flue gases.

A number of processes, termed "wet processes," are the outcome of the method introduced by Thenard in 1801. The Thenard process consisted of the precipitation of white lead from a solution of basic lead acetate, using furnace gases containing from 12 to 17 per cent carbon dioxide. The improvements which have been made in the process deal with the method of obtaining the basic acetate solution, use of pure carbonic acid gas, conversion under pressure, etc., and are of practical importance only.

The Bischof process depends on the conversion of a specially prepared lead hydrate into carbonate, using a definite quantity of normal acetate of lead as catalyst. Many of the above processes are supplemented by purification methods for the removal of uncorroded lead; lead acetate, and neutral lead carbonate which lead; lead acetate, and neutral lead carbonate which
would adversely affect the product as a paint material. Precipitation by alkaline carbonates, though of ten suggested, has not proved to be of practical value further, as yet, the electrolytic processes have made no progress.

White lead is sold either as a dry powder or ground in oil in the form of paste containing from 6 to 8 per cent of linseed oil. Commercial white lead approximates to the composition $2 \mathrm{PbCO}_{3}, \mathrm{~Pb}(\mathrm{OH})_{2}$, and it is frequently stated that this composition is the mos desirable, though there is little to support this conclusion. The exact chemical composition of a pigment is of little or no value in determining. its pigment value, and its importance is much overrated, while the physiand its importance is much overrated, while the physiquently ignored.

Chemically there is little difference between the products of the present processes, but physical differences are more common, and the successful workin of a white lead process lies in the control of the factors which produce the best physical condition commensurate with a reasonable latitude as regards chemical composition.

The bulk of the white lead sold is pure, but a s mall quantity of " "reduced" white lead finds application. of barytes on a recognized scale, and white lead containing barytes must be marked "reduced." Few cases of fraudulent adulteration take place in England owing to the efforts of manuacturers in this connection.

The specific gravity of white lead is higher than that of any of its substitutes, the figure varies somewhat according to the method of preparation and chemical composition, but 6.5 may be considered an average figure.

Basic Sulphate of Lead or Sublimed Lead.-The use of basic lead sulphate as a paint material was first suggested by Bartlett in 1866, and a process was patented by him in $\mathbf{1 8 7 0}$ for its preparation from Galena. The progress made was comparatively slow until 'within recent years, but now the product has very extensive use in the United States of Americe, and more recently its manufacture has been introduced into England. The process consists in the furnacing of high grade
galena which has received a preliminary jigging and crushing. The furnacing is carried out in a special type of blast furnace, whereby lead sulphide is volar tilized and oxidized. The resulting basic sulphate is collected dry in goose-neck condensers and bag filters.

The chemical composition of basic sulphate varies between the compounds ( $\mathrm{PbO}, \mathrm{PbSO}_{4}$ ), and ( $\mathrm{PbO}$, $2 \mathrm{PbSO}_{4}$ ). The impurities consist of foreign substances either volatilized from the galena or carried over mechanically by the blast. When zinciferous galena is used notable quantity (about 5 per cent) of zinc is found in the product. The slight creamy color frequently obsorved is attributed to iron. The product consists of particles of uniform size in an extremely fine state of division.

It is sold dry, or in an oil paste containing abou 9 per cent linseed oil. The specific gravity is approximately 6.2.

Zinc Oxide.-The use of zinc oxide as a substitute or white lead was first suggested by Guyton de Morweau about 1780, whose suggestion encouraged Courtois who had also been engaged on the problem, to undertake its manufacture on a large scale, and in conse quence Courtois established businesses in Dijon and Paris. The progress made during the next sixty year was very slow in spite of the support of men of th standing of Fourcroix, Berthollet, and Vauquelin, and it was not until about 1844 that Jean Leclaire commenced the famous campaign which after long-drawn truggles culminated in the French Act of July 20th 1909 , interdicting the use of $\cdot$ white lead in all pain work on buildings after 1914 under certain conditions. Since its early introduction many improvement have been effected in the method of manufacture and quality, with the result that zinc oxide has now very extensive application.

Two types of zinc oxide are marketed, known as "indirect" and "direct," and these are prepared as follows: "Indirect" oxide is prepared from spelter, and is therefore comparatively chemically pure. The process consists of the oxidation by air blast of the
zinc vapor obtained by the distillation of zine from retorts of special construction.

The oxide so produced is passed through a serie of cooled pipes, thence to settling chambers. Th purity and color of the oxide is determined by the distance it is carried in the settling chamber, and th product is graded by this means. Qualities are branded in seals, e. g., green seal, red seal, etc. This process is used in Europe and to some small extent in Penntively free of impurities.

The "direct" process, which produces zine oxide direct from the ore, is of American origin, and was originally due to S. T. Jones, who, in 1850 , erected a special furnace for this purpose. The commercia application of the process was established five years later by Wetherill, who had

During the last thirty years the output of this process has increased enormously. Wetherill first applied the process to the New Jersey Franklinite ores. Th New Jersey ore is a complex of Franklinite, Willemite, Calcite and occasionally Zincite, having an averag zinc content of 25 per cent. Process takes place in thre stages, viz.: (1) Removal of sulphur from ore by roasting; (2) magnetic separation and jigging of roasted product; and (3) reduction of zinc oxide in ore to metal with volatilization and subsequent oxidation. The oxide is collected in chambers followed by bag filters. The produst so obtained compares favorably in chemical purity with that obtained by the "indirect" process, but it was found that this was not maintained when western ores were treated. This is due to the which are blendes, and contain sulphur in quantity towhich are blendes, and cosity toyields large quantities of sulphur dioxide, and in some yields large quantities of sulphur dioxide, and in some
cases this is used for the manufacture of sulphuric acid.

The subsequent treatment of the roasted ore is similar to that adopted for eastern ore. Lead (as basic sulphate) is present in western oxide up to about $6 \mathrm{pe}$ cent. The "direct" process has been applied to European ores, whish are somewhat similar in composition to the wastern ore, and here again the impurities affect the final product, so that European direct oxides almost invariably contain lead, and this is recognized in some Continental specifications. The color of direct oxides, ther than New Jersey, is not equal to that of the "indirect" oxides, and great care must be taken to avoid the formation of zinc sulphate in the product, owing to its injurious effect on the paint film.

The product is graded into qualities according to color and lead content, the different grades being distinguished as red seal, green seal, etc. At present there is no generally accepted opinion as to the superiority of one type of oxide over the other, though it is claimed by some that the small quantity of basic lead sulphate present in some "direct" oxides increases the stability of the resulting paint film.

In America so-called "leaded zincs" are prepared by furnacing mixtures of galena and blende. These contain from 20 to 30 per cent of basic lead sulphate, together with 70 to 80 per cent. zinc oxide.

$\nabla$ arious wet processes (precipitation and electrolytic) have been suggested for the manufacture of zinc oxide, but as yet have not assumed commercial importance. Zinc oxide is sold either as a dry powder (specific gravity about 5.6) or as an oil paste containing 14 to 20 per cent of linseed oil.

Lithopone.-Lithopone or lithophone are generic ames given to a class of pigments of varying composition. The highest grade lithopone contains about 28 per cent zinc sulphide, 70 per cent barium sulphate, 2 per cent zinc oxide, while the lower grades contain less zinc sulphide and more barium sulphate, the reduction usually being effected by mixing the high grade with diluents:

The manufacture of lithopone was first patented by J. B. Orr in 1876, and the product sold as Orr's White Enamel and Charlton-White. In 1876, Griffith, and 1879, Griffith and Crawley, were granted patents for improved processes. Since that date very numerous patents have been obtained, generally of little practical value. The manufacture of lithopone, although originally an English process, has not made much headway in England, but on the Continent of Europe the process has assumed huge proportions, doubtless owing to anti-white lead agitations. The U. S. A. production is also considerable.

Products of varying composition (frequently mixtures of lithopone with other white pigments) are sold under fancy trade names, which give no indication as to composition. The term "white zinc" is sometimes wrongly applied to lithopone. Zine white or white zine should ways be zinc oxide.

Lithopone is prepared by the mutual precipitation of barium sulphate, and zinc sulphide using solutions of barium sulphide and zinc sulphate. Mutual precipitation insures homogenity of product. which is most desired in a paint material.

The solution of zine sulphate is prepared direct from the ore in Germany, while the American practice is to dissolve spelter or by-products containing zinc. Barium sulphide is prepared from barium sulphate by reduction with carbon in specially constructed urnaces.

The furnace mass is leached with water and the solution so obtained purified. The solutions of barium and zinc must be pure, otherwise precipitation carries down impurities which seriously affect the color.

The precipitate of lithopone is dried and furnaced at high temperature, and is then quenched in cold water, which increases the density and at the same time reduces the oil absorption.

In the operation of calcining, a small portion of the zinc sulphide is converted into oxide. Various additions are made to the furnace charge to minimize this oxidation. The substance added being one which will on volatilization produce an inert atmosphere in the furnace charge and so prevent oxidation. The quenched material is ground in water and dried.

Lithopone is at times curiously sensitive to light; in strong sunlight a painted surface sometimes rapidly becoming grey-black in color. The white color is regained in the absence of light. The cause of this phenomena is not understood, and though many remedies have been suggested, none can claim to be absolutely effective, the change occurring in spesially treated products with disconcerting irregularity.

Lithopone is sold as a dry powder, specific gravity about 4.2 , or as an oil paste containing from 17 to 18 per cent linseed oil.

Ready-mixed Paints. - The foregoing covers practically all the white pigments in use as bases for oil prin 5 . 


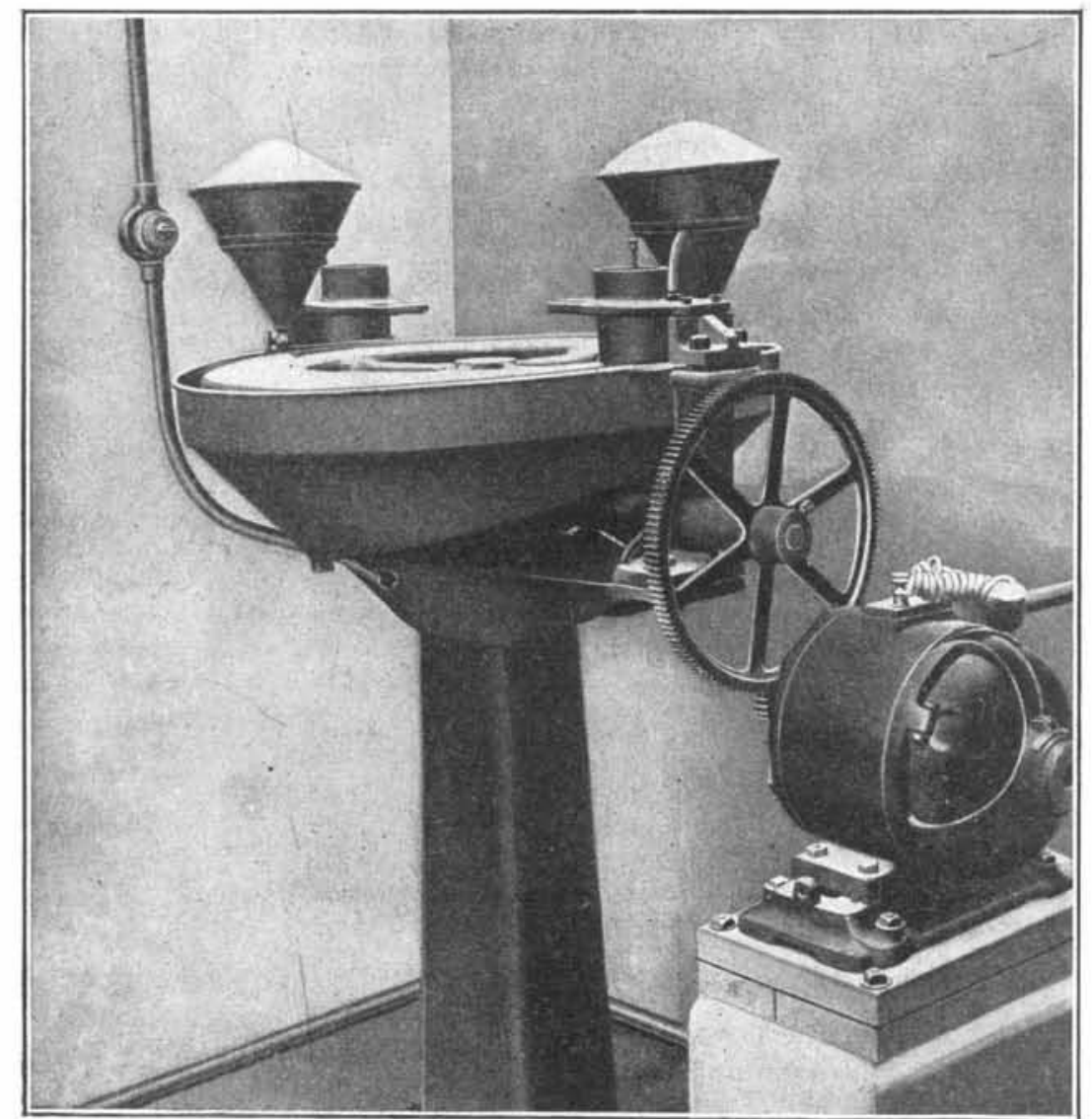

Fig. 1.-Dorry Hardness Machine.

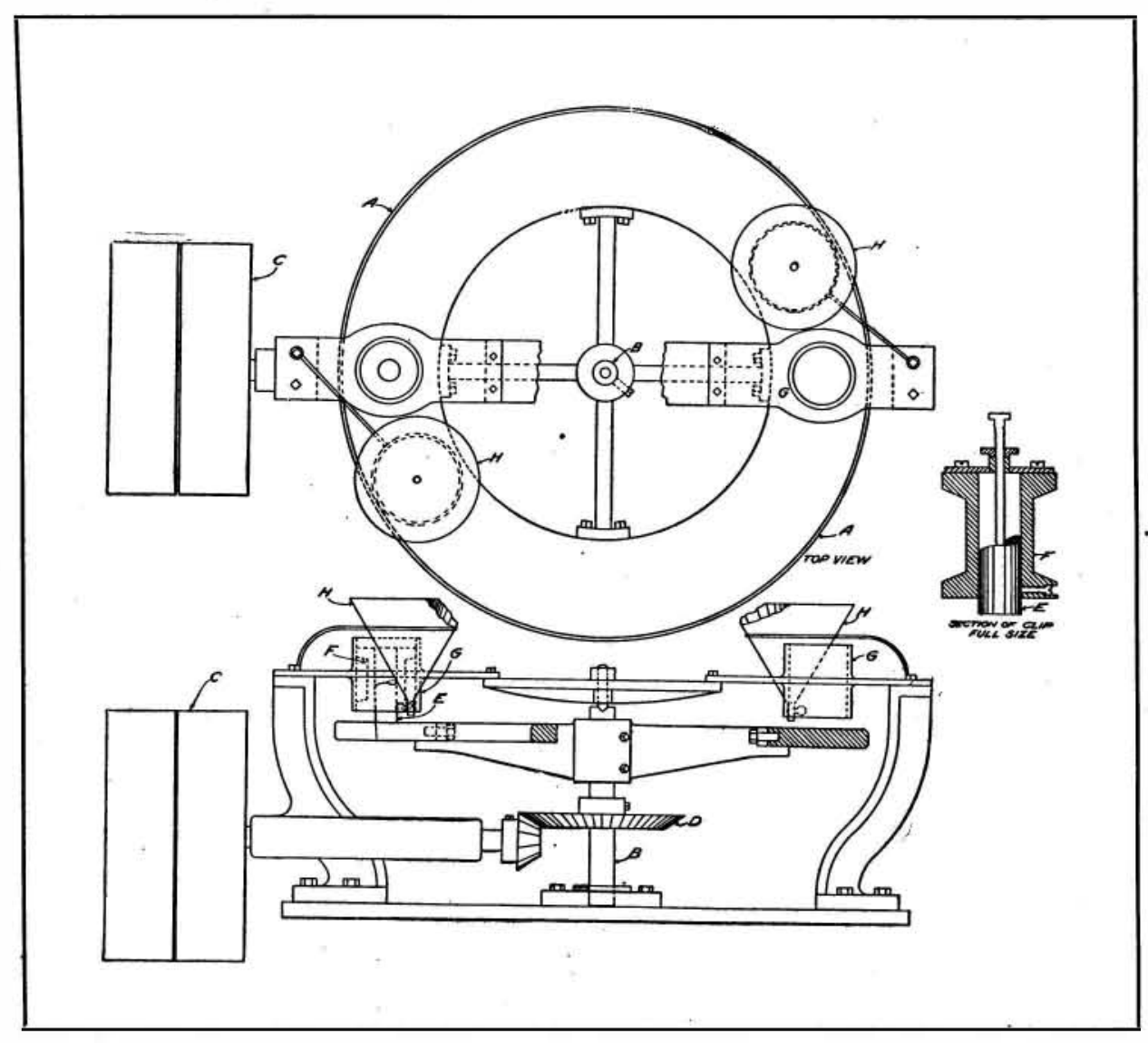

Fig. 2.-Details of Dorry Hardness Machine.

\section{The Physical Testing of Rock for Road Building-I*}

\section{The Methods Used and the Results Obtained}

By Albert T. Goldbeck and Frank H. Jackson, Jr.

The study of the physical and chemical properties of road materials by means of laboratory tests has been carried on in a more or less desultory fashion for over 30 years. Quite recently, however, the development of more systematic and greatly improved methods for testing, with a consequent augmented accumulation of data, has given the results obtained a much more practical significance than formerly.

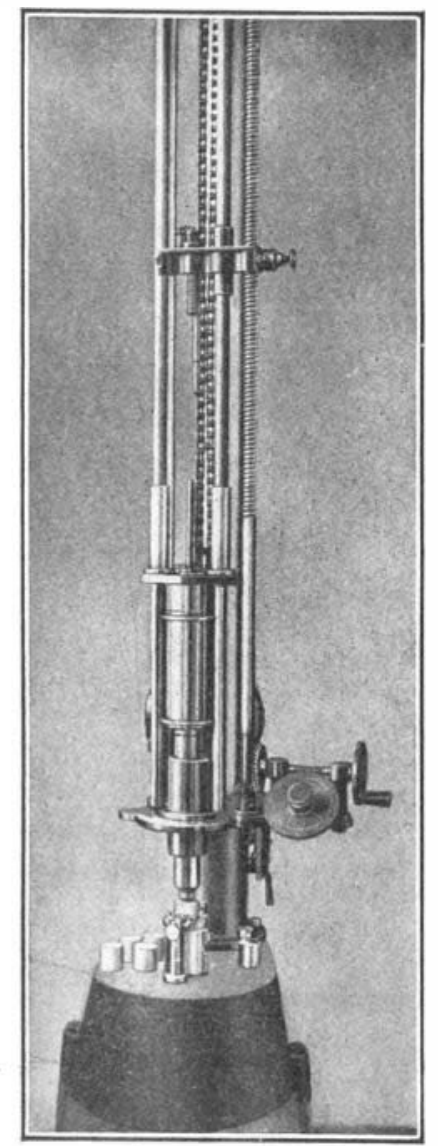

Fig. 3.-Page Impact Testing Machine.

In December, 1900, the United States Government because of the growing importance of the problem of testing road materials, established a laboratory in the Bureau of Chemistry of the Department of Agrieulture, Bur the direction of Mr. Page. This laboratory was under transferred in 1905 to the Office of Public Roads, where its present organization was developed.

The present general interest in the necessity for good road construction has resulted, quite recently, in

- O丹ilce of Public Roads, Bulletin 44. the establishment of laboratories in many technical institutions, both in this country and abroad, as well as in the various state highway commissions.

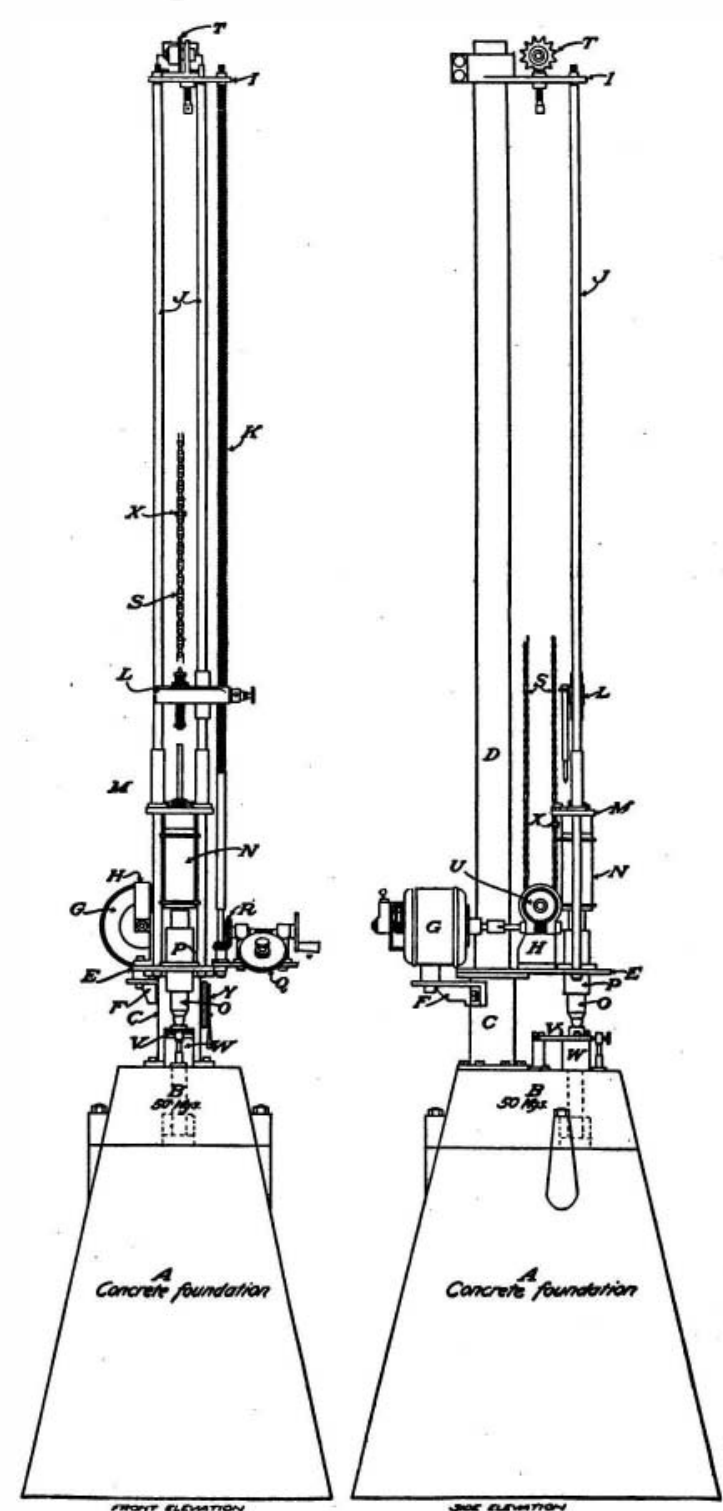

Fig. 4.-Details of Page Impact Testing Machine.

The fact that a large number of samples are submitted for investigation and reported on annually by these laboratories is good evidence of the value of the information received by the road engineer through the agency of laboratory tests on the relative worth of the materials which he proposes to use in road constructhese tests is the object of this bulletin to describe results.

Agencies Destructive of Roads.

The surface of a road is subject to deterioration due to the effects of $(a)$ mechanical, $(b)$ chemical, and $(c)$ physical agencies whose disintegrating action may be more or less combated by proper construction and maintenance with carefully selected materials. The individual stones in a macadam road are bound together by finer particles and rock powder, and the ideal condition is that in which there is always just enough dust existing to cement these stones together tightly.

(a) Mechanical Agencies.-The action of trafflc on a road surface is purely mechanical. The severe impact of horses' leet tends to disturb the individual stones by loosening the binding material. At the same

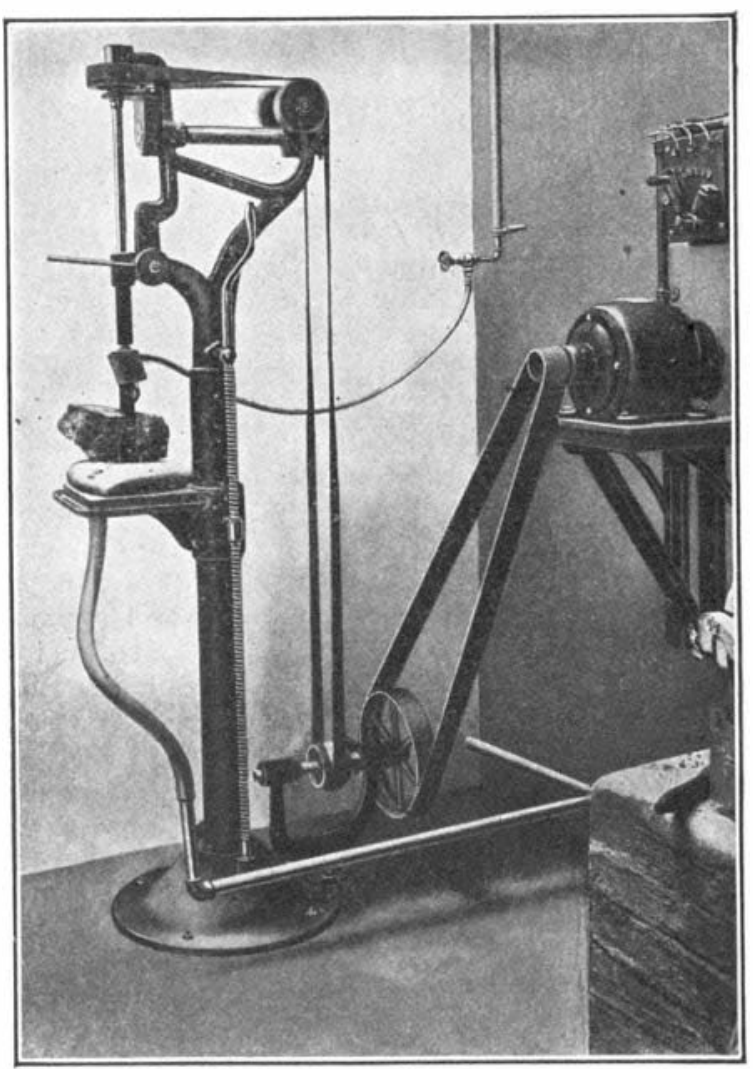

Fig. 5.-Method of Irilling Core from Rock Sample With Diamond Core Drill. 